\title{
Differences in Characteristics, Hospital Care and Outcomes between Acute Critically Ill Emergency Department Patients with Early and Late Do-Not-Resuscitate Orders
}

\author{
Julia Chia-Yu Chang ${ }^{1,2}$, Che Yang ${ }^{3}$, Li-Ling Lai ${ }^{3}$, Ying-Ju Chen ${ }^{1,2}$, Hsien-Hao Huang ${ }^{1,2,4}$, Ju-Sing Fan ${ }^{1,2}$, \\ Teh-Fu Hsu ${ }^{1,2}$ and David Hung-Tsang Yen 1,2,4,5,*
}

1 Department of Emergency Department, Taipei Veterans General Hospital, Taipei 11217, Taiwan; juliahazard@hotmail.com (J.C.-Y.C.); yjchen0304@gmail.com (Y.-J.C.); hhhuang@vghtpe.gov.tw (H.-H.H.); jsfan@vghtpe.gov.tw (J.-S.F.); tfhsu@vghtpe.gov.tw (T.-F.H.)

2 School of Medicine, National Yang-Ming University, Taipei 11221, Taiwan

3 Department of Nursing, Taipei Veterans General Hospital, Taipei 11217, Taiwan; cyang@vghtpe.gov.tw (C.Y.); lllai@vghtpe.gov.tw (L.-L.L.)

4 Institute of Emergency and Critical Care Medicine, College of Medicine, National Yang-Ming University, Taipei 11221, Taiwan

5 Department of Emergency Medicine, National Defense Medical Center, Taipei 11217, Taiwan

* Correspondence: hjyen@vghtpe.gov.tw; Tel.: +886-2-28757371; Fax: +886-2-28757842

Citation: Chang, J.C.; Yang, C.; Lai, L.-L.; Chen, Y.-J.; Huang, H.-H.; Fan, J.-S.; Hsu, T.-F.; Yen, D.H. Differences in Characteristics, Hospital Care and Outcomes between Acute Critically Ill Emergency Department Patients with Early and Late Do-Not-Resuscitate Orders. Int. J. Environ. Res. Public Health 2021, 18, 1028. https:// doi.org/10.3390/ijerph18031028

Received: 29 November 2020

Accepted: 21 January 2021

Published: 25 January 2021

Publisher's Note: MDPI stays neutral with regard to jurisdictional claims in published maps and institutional affiliations.

Copyright: (c) 2021 by the authors. Licensee MDPI, Basel, Switzerland. This article is an open access article distributed under the terms and conditions of the Creative Commons Attribution (CC BY) license (https:// creativecommons.org/licenses/by/ $4.0 /)$.

\begin{abstract}
Background: A do-not-resuscitate (DNR) order is associated with an increased risk of death among emergency department (ED) patients. Little is known about patient characteristics, hospital care, and outcomes associated with the timing of the DNR order. Aim: Determine patient characteristics, hospital care, survival, and resource utilization between patients with early DNR (EDNR: signed within $24 \mathrm{~h}$ of ED presentation) and late DNR orders. Design: Retrospective observational study. Setting/Participants: We enrolled consecutive, acute, critically ill patients admitted to the emergency intensive care unit (EICU) at Taipei Veterans General Hospital from 1 February 2018, to 31 January 2020. Results: Of the 1064 patients admitted to the EICU, 619 (58.2\%) had EDNR and 445 (41.8\%) LDNR. EDNR predictors were age $>85$ years (adjusted odd ratios (AOR) 1.700, 1.027-2.814), living in long-term care facilities (AOR 1.880, 1.066-3.319), having advanced cardiovascular diseases (AOR $2.128,1.039-4.358)$, "medical staff would not be surprised if the patient died within 12 months" (AOR $1.725,1.193-2.496)$, and patients' family requesting palliative care (AOR 2.420, 1.187-4.935). EDNR patients underwent lesser endotracheal tube (ET) intubation $(15.6 \%$ vs. $39.9 \%, p<0.001)$ and had reduced epinephrine injection $(19.9 \%$ vs. $30.3 \%, p=0.009)$, ventilator support $(16.7 \%$ vs. $37.9 \%$, $p<0.001)$, and narcotic use ( $51.1 \%$ vs. $62.6 \%, p=0.012)$. EDNR patients had significantly lower 7 -day $(p<0.001), 30$-day $(p<0.001)$, and 90-day $(p=0.023)$ survival. Conclusions: EDNR patients underwent decreased ET intubation and had reduced epinephrine injection, ventilator support, and narcotic use during EOL as well as decreased length of hospital stay, hospital expenditure, and survival compared to LDNR patients.
\end{abstract}

Keywords: emergency department; intensive care unit; do-not-resuscitate; hospital care

\section{Introduction}

Although the main responsibilities of emergency physicians (EPs) when treating acute critically ill emergency department (ED) patients include initial resuscitation, stabilization, rapid diagnosis, and curative treatment, aggressive resuscitation may not be appropriate or desired when managing seriously ill patients with advanced chronic illness with trajectories of dying. Early conversations with patients and surrogates regarding aggressive resuscitative measures are critical with respect to patient autonomy and appropriately tailored care. Do-not-resuscitate (DNR) orders are an alternative for patients at the end of life [1], to prevent nonbeneficial resuscitative measures and unnecessary suffering when 
patients are imminently dying [2,3]. Placement of DNR orders is variable between different types of hospitals and based on differing patient demographic factors $[4,5]$.

In theory, the DNR order itself should not directly impact care until the moment of cardiac arrest. However, early DNR (EDNR: order placement within $24 \mathrm{~h}$ of ED presentation) was found to directly influence both resuscitative and ancillary care [6] and resulted in a decrease in potentially critical hospital interventions, with wide variability in practice patterns between hospitals [3]. EDNR often is a proxy of patient's underlying disease, prehospital frailty, and burden of comorbidities [4], an independent predictor of 28-day mortality [7]; and a strong predictor of short-term mortality risk [8]. The aim of the study was to determine differences in patient characteristics, demographics, hospital care, survival, and resource utilization between EDNR and late DNR (LDNR: after $24 \mathrm{~h}$ of ED admission) among ED patients admitted to the ICU.

\section{Methods}

\subsection{Study Design}

This was a retrospective cohort study of adult ED patients ( $\geq 18$ years) who presented to the ED of Taipei Veterans General Hospital (TVGH) from 1 February 2018, to 31 January 2020. This project was approved by the TVGH Institutional Research Board, which waived the need for patient consent (IRB No: 2020-11-010BC).

\subsection{Study Setting}

TVGH, a 3000-bed university-affiliated medical center, has an annual ED census of $85,200 \pm 1812$ over the past five years. The emergency intensive care unit (EICU) is a 13-bed ICU within the ED [9] where acute critically ill patients who are not admitted to the specialized ICU immediately after initial ED resuscitation and stabilization receive intensive care. The primary goal of the EICU setting was to implement continuous emergency and critical quality of care within ED prior to available specialty ICU transfer. The operative system in our EICU is semi-open model, that both the EPs and physicians in other subspecialties cooperatively take care of all admission patients. This system was supervised by Emergency Quality Control Committee.

\subsection{Patient Population}

Patients with a diagnosis meeting the criteria for acute severe critical illness (item A) and who also fulfilled two of the criteria for initiating PCC (item B) were categorized as the PC-eligible group (Table 1). The others were categorized as the PC-ineligible group. Palliative care consultation (PCC) screening was initiated for acute critically ill patients aged $\geq 18$ years who were admitted to the EICU from 1 February 2018, to 31 January 2020. Exclusion criteria were age $<18$ years and medical records with incomplete or missing data. DNR orders are orders to withhold resuscitative measures including CPR, intubation, defibrillation, cardioactive drugs, or assisted ventilation. Patients who did not sign the DNR form on admission $(n=1565)$ and patients who signed the DNR form before admission $(n=185)$ were excluded (Appendix A). Patients were considered to have a preexisting DNR order if a DNR order was found in the patient's chart dated before the day of admission. The primary exposure variable was whether an order to limit resuscitation efforts was written within the first $24 \mathrm{~h}$ of admission (EDNR). 
Table 1. The screening items for needs assessment of palliative care consultation among 1064 patients at the time of admission.

$\begin{array}{ccccc}\text { Items } & \text { Overall } & \text { Early DNR } & \text { Late DNR } & p \text {-Value } \\ & n=1064(\%) & n=619(\%) & n=445(\%) & \\ \end{array}$

A. Acute critical and life-limiting illness

1. Advanced cancer, metastatic or locally aggressive disease

$\begin{array}{cccc}204(19.2) & 123(19.9) & 81(18.2) & 0.495 \\ 11(1.0) & 7(1.1) & 4(0.9) & 0.712 \\ 20(1.9) & 14(2.3) & 6(1.3) & 0.279 \\ 26(2.4) & 19(3.1) & 7(1.6) & 0.119 \\ 60(5.6) & 48(7.8) & 12(2.7) & <0.001\end{array}$

2. Advanced COPD who needs long-term oxygen therapy or respiratory

failure requiring assisted ventilation

3. End-stage liver disease, e.g., cirrhosis, that repeatedly appears with jaundice, ascites, peritonitis, hepatic coma, esophageal varices

4. Acute or chronic renal failure, decision of not receiving dialysis

5. Advanced cardiovascular diseases (chronic heart failure NYHA III or

$\mathrm{IV}$, chest pain, or dyspnea while in minimal exercise or exertion, or

devastating inoperable peripheral vascular diseases) *

6. Advanced central neurological diseases (e.g., stroke, dementia) in

long-term bed-bound, combined with repeatedly or severely progressive

deterioration or recurrent pneumonia, shortness of breath, or respiratory

failure requiring hospital admission *

7. Septic shock, ARDS, multiple organ failure, or impending death (other devastating diseases) *

8. Very severely frail (completely dependent, approaching the end-of-life, CSHA-CFS > scale 8 and 9) *

B. The unmet palliative care needs

1. Medical care staffs would not be surprised if the patient died within 12

months of this episode (surprise question) *

2. Appearing progressive functional deterioration with $\geq 3$ ADLs

needing for assistance

3. Appearing biopsychosocial discomforts needing hospital admission *

4. Patients with three or more unexpected emergency department visits or hospital admissions within 6 months, with symptoms consistent with a terminal or degenerative chronic medical condition *

5. Patients Weight loss $10 \%$ or $\mathrm{BMI} \leq 18$ within 6 months

6. Bed-bound patients with long-term unhealed bed sore or ulceration *

7. Needing complicated medical care and assistance of medical decisions, including do-not-resuscitate order, ventilator, or nutritional supports *

8. Patient's family request of palliative care *

$\begin{array}{cccc}544(51.1) & 374(60.4) & 170(38.2) & <0.001 \\ 363(34.1) & 226(36.5) & 137(30.8) & 0.052 \\ 368(34.6) & 247(39.9) & 121(27.2) & <0.001 \\ 235(22.1) & 159(25.7) & 76(17.1) & 0.001 \\ 10(0.9) & 8(1.3) & 2(0.4) & 0.160 \\ 54(5.1) & 39(6.3) & 15(3.4) & 0.032 \\ 632(59.4) & 424(68.5) & 208(46.7) & <0.001 \\ 53(5.0) & 41(6.6) & 12(2.7) & 0.004\end{array}$

Results expressed as number (\%) for categorical variables; Of the 1064 screened patients, 36.7\% (390/1064) has one item, 27.1\% (288/1064) has 2 items, and $1.7 \%(18 / 1064)$ has 3 items of acute critical and life-limiting illnesses. Of the 1064 patients having one or more items of acute critical and life-limiting illnesses, 1.2\% (13/1064) has one item, 9.4\% (100/1064) has 2 items, 28\% (298/1064) has 3 items, 22.9\% $(244 / 1064)$ has 4 items, and; $3.3 \%(35 / 1064)$ has 5 or more items of the unmet palliative care needs; COPD = chronic obstructive pulmonary disease; NYHA = New York Heart Association; ARDS = adult respiratory distress syndrome; CSHA-CFS = Chinese-Canadian study of health and aging clinical frailty scale $\mathrm{ADL}=$ activities of daily living; $\mathrm{BMI}=$ body mass index; ${ }^{*} p<0.05$ is considered statistically significant using chi-squared analysis or Fisher's exact test.

\subsection{Palliative Care Assessment and Data Collection}

Utilization criteria were formulated by palliative care (PC) and hospice specialists and adopted to identify patients at high risk of poor clinical outcomes as their care commonly involves prolonged use of advanced medical resources or technologies [10]. Two trained authors entered the abstracted data for study analyses. The information, time and date of each DNR orders were collected via inpatient electronic medical record systems.

\subsection{Outcome Measures}

Data collected were patient characteristics, hospital care, medical resource utilization, hospital length of stay (LOS), and total expenditures and in-hospital mortality. Hospital care included endotracheal (ET) intubation and ventilator support, cardiopulmonary resuscitation (CPR), cardioversion/defibrillation, epinephrine injection, vasopressor therapy, cardiac pacemaker insertion, extracorporeal membrane oxygenation (ECMO), endotracheal removal, and narcotic use. 


\subsection{Data Analysis}

Data are expressed as mean \pm SD for continuous variables and number (\%) for categorical variables. Data distribution was assessed using the Kolmogorov-Smirnov test. Comparisons of numerical variables were performed using an unpaired $t$-test (parametric data) or Mann-Whitney U test (nonparametric data). Categorical variables were compared using the two-sided chi-square or Fisher's exact test. Factors showing statistical significance $(p<0.05)$ in the univariate analysis were included in the multiple regression analysis. Survival time was calculated from the date of admission to the date of death using the Kaplan-Meier method, and the difference in survival time between the eligible and ineligible groups was compared using the log-rank test. $p<0.05$ was considered statistically significant. Statistical analysis was performed using SPSS software version 22.0 (SPSS Inc., Chicago, IL, USA).

\section{Results}

A total of 1064 patients were recruited for the study; 619 (58.2\%) had EDNR and 445 $(41.8 \%)$ LDNR. The screening items for PC consultation at the time of EICU admission are shown in Table 1. Patients with EDNR had more advanced cardiovascular diseases, advanced central neurological diseases, septic shock, adult respiratory distress syndrome (ARDS), multiple organ failure or impending death, and were very severely frail (all $p<0.001)$. The clinical characteristics of EDNR and LDNR patients are compared in Table 2. The mean age of EDNR patients were older than LDNR ( 80.8 vs. 77.3 years, $p<0.001)$. While more LDNR patients lived with family $(84.9 \%$ vs. $78.2 \%)$, more EDNR patients lived in veterans' homes ( $4.4 \%$ vs. $2.3 \%$ ) and long-term care facilities $(8.6 \%$ vs. $4.7 \%$, all $p=0.035)$. Patients with EDNR had reduced length of hospital stay (17.8 \pm 18.4 days vs. $30.3 \pm 31.7$ days, $p<0.001)$, and lower total hospital expenses $(246,684 \pm 266,447$ new Taiwan dollar (NTD) vs. $468,532 \pm 476,382, p<0.001$ ).

Table 3 shows the univariate and multiple logistic regression analyses of clinical characteristics between EDNR and LDNR patients. The risk factors associated with EDNR were age $>85$ years (AOR 1.700, $p=0.039$ ), living in long-term care facilities (AOR 1.880, $p=0.029$ ), presence of advanced cardiovascular diseases (A5) (AOR 2.128, $p=0.039$ ), patients whom medical staff would not be surprised if they died within 12 months (B1) (AOR 1.725, $p=0.004$ ), and patients whose family requested PC (B8) (AOR 2.420, $p=0.015$ ). The screening items (item A and item B) for assessment of palliative care consultation at the time of admission were listed in full in Table 1.

Differences in hospital care between EDNR and LDNR patients are compared in Table 4. Patients with EDNR received less endotracheal tube (ET) intubation procedures $(15.6 \%$ vs. $39.9 \%, p<0.001)$, less epinephrine injection ( $19.9 \%$ vs. $30.3 \%, p=0.009)$, less ventilator support $(16.7 \%$ vs. $37.9 \%, p<0.001)$, and less narcotic use $(51.1 \%$ vs. $62.6 \%$, $p=0.012$.

Table 5 shows multiple logistic regression analyses of hospital care between patients with mortality with EDNR and LDNR. Patients with EDNR underwent lesser ET intubation procedures (AOR 0.198, $p=0.007$ ) and had reduced narcotic use (AOR 0.518, $p=0.001$ ).

Figure 1 shows the Kaplan-Meier curve for survival between patients with EDNR and LDNR. Patients with EDNR had a significantly lower 7-day, 30-day and 90-day survival. 
Table 2. Comparison of clinical characteristics between early DNR and late DNR patients.

\begin{tabular}{|c|c|c|c|c|}
\hline \multirow{2}{*}{ Variable } & Overall & Early DNR & Late DNR & \multirow{2}{*}{$p$-Value } \\
\hline & $n=1064(\%)$ & $n=619(\%)$ & $n=445(\%)$ & \\
\hline Age, year * & $80.8 \pm 14.2$ & $83.3 \pm 12.8$ & $77.3 \pm 15.4$ & $<0.001$ \\
\hline$<65$ & $157(14.8)$ & $73(11.8)$ & $84(18.9)$ & \\
\hline $65-75$ & 137 (12.9) & $54(8.7)$ & $83(18.7)$ & \\
\hline $75-85$ & $219(20.6)$ & $122(19.7)$ & $97(21.8)$ & \\
\hline$>85$ & $551(51.8)$ & $370(59.8)$ & $181(40.7)$ & \\
\hline Female sex & $399(37.5)$ & $234(37.8)$ & $165(37.1)$ & 0.81 \\
\hline \multicolumn{5}{|l|}{ Insurance status * } \\
\hline National health insurance only & $621(58.4)$ & $338(54.6)$ & $283(63.6)$ & \multirow{2}{*}{0.003} \\
\hline With Medicaid & $443(41.6)$ & $281(45.4)$ & $162(36.4)$ & \\
\hline \multicolumn{5}{|l|}{ Living conditions * } \\
\hline With family & $860(81.0)$ & $484(78.2)$ & $376(84.9)$ & \multirow{5}{*}{0.035} \\
\hline Veterans home & $37(3.5)$ & $27(4.4)$ & $10(2.3)$ & \\
\hline Long-term care facilities & $74(7.0)$ & $53(8.6)$ & $21(4.7)$ & \\
\hline Solitary living & $70(6.6)$ & $42(6.8)$ & $28(6.3)$ & \\
\hline Others & $21(2.0)$ & $13(2.1)$ & $8(1.8)$ & \\
\hline \multicolumn{5}{|l|}{ Marital status } \\
\hline Single & $93(8.8)$ & $54(8.7)$ & $39(8.8)$ & \multirow{4}{*}{0.287} \\
\hline Married & $642(60.6)$ & $363(58.7)$ & $279(63.3)$ & \\
\hline Divorced & $37(3.5)$ & $20(3.2)$ & $17(3.9)$ & \\
\hline Widow or widower & $387(27.1)$ & $181(29.3)$ & $106(24.0)$ & \\
\hline \multicolumn{5}{|l|}{ Religion } \\
\hline Taoism & $189(17.8)$ & $108(17.4)$ & $81(18.3)$ & \multirow{5}{*}{0.478} \\
\hline Buddhism & $355(33.5)$ & $205(33.1)$ & $150(33.9)$ & \\
\hline Catholic/Christian & $97(9.1)$ & $53(8.6)$ & $44(10.0)$ & \\
\hline Others & $11(1.0)$ & $9(1.5)$ & $2(0.5)$ & \\
\hline None & $409(38.5)$ & $244(39.4)$ & $165(37.3)$ & \\
\hline \multicolumn{5}{|l|}{ Educational level } \\
\hline Higher than high school & $444(42.0)$ & $244(39.5)$ & $200(45.5)$ & \multirow[t]{2}{*}{0.055} \\
\hline Lower than high school & $613(58.0)$ & $373(60.5)$ & $240(54.5)$ & \\
\hline Current alcohol consumption & $18(1.7)$ & $11(1.8)$ & $7(1.6)$ & 0.796 \\
\hline Current smoker * & $69(6.5)$ & $32(5.2)$ & $37(8.3)$ & 0.041 \\
\hline \multicolumn{5}{|l|}{ TTAS * } \\
\hline Emergent (triage 1) & $404(38.1)$ & $258(41.9)$ & $146(32.9)$ & \multirow{3}{*}{0.004} \\
\hline Urgent (triage 2) & $371(35.0)$ & $212(34.4)$ & $159(35.8)$ & \\
\hline Non-urgent (triage 3,4 ) & $285(26.9)$ & $146(23.7)$ & 139 (31.3) & \\
\hline Glasgow Coma Scale * & $10.8 \pm 4.5$ & $10.4 \pm 4.6$ & $11.4 \pm 4.2$ & \multirow{4}{*}{$<0.001$} \\
\hline $13-15$ & $536(50.4)$ & $291(47.0)$ & $245(55.1)$ & \\
\hline $5-12$ & $366(34.4)$ & $214(34.6)$ & $152(34.2)$ & \\
\hline $3-4$ & $162(15.2)$ & $114(18.4)$ & $48(10.8)$ & \\
\hline $\begin{array}{l}\text { Mean blood pressure in the emergency } \\
\text { department (ED) (mmHg) }\end{array}$ & $91.1 \pm 24.2$ & $90.6 \pm 24.3$ & $91.9 \pm 24.0$ & 0.369 \\
\hline Charlson Comorbidity Index & $6.7 \pm 2.5$ & $6.8 \pm 2.3$ & $6.6 \pm 2.7$ & 0.414 \\
\hline$\leq 3$ & $59(5.5)$ & $20(3.2)$ & $39(8.8)$ & \\
\hline$\overline{4}-6$ & $496(46.6)$ & $298(48.1)$ & $198(44.5)$ & \\
\hline$\geq 7$ & $509(47.8)$ & $301(48.6)$ & $208(46.7)$ & \multirow{5}{*}{$<0.001$} \\
\hline APACHE II score at admission * & $21.8 \pm 8.4$ & $22.7 \pm 8.4$ & $20.6 \pm 8.2$ & \\
\hline 0-14 & $204(19.2)$ & $101(16.3)$ & $103(23.1)$ & \\
\hline $15-24$ & $486(45.7)$ & $277(44.7)$ & $209(47.0)$ & \\
\hline$>24$ & $374(35.2)$ & $241(38.9)$ & $133(29.9)$ & \\
\hline Hospital length of stay (day) * & $23.1 \pm 25.6$ & $17.8 \pm 18.4$ & $30.3 \pm 31.7$ & $<0.001$ \\
\hline Total hospital expense (point) * & $339,468 \pm 384,772$ & $246,684 \pm 266,447$ & $468,532 \pm 476,382$ & $<0.001$ \\
\hline Inhospital mortality & $480(45.1)$ & $282(45.6)$ & $198(44.5)$ & 0.731 \\
\hline
\end{tabular}

Results expressed as number (\%) for categorical variables and mean \pm standard deviation for numerical variables; TTAS = Taiwan Triage and Acuity Scale; ED = emergency department; APACHE = Acute Physiology and Chronic Health Evaluation; ICU = intensive care unit; ${ }^{*} p<0.05$ is considered statistically significant using Mann-Whitney U test or chi-squared analysis. 
Table 3. Univariate and multiple logistic regression analyses of clinical characteristics between early DNR and late DNR patients.

\begin{tabular}{|c|c|c|c|c|c|c|}
\hline \multirow{2}{*}{ Variable } & \multicolumn{3}{|c|}{ Univariate Analysis } & \multicolumn{3}{|c|}{ Multiple Logistic Regression } \\
\hline & OR & $95 \%$ CI & $p$ & AOR & $95 \%$ CI & $p$ \\
\hline \multicolumn{7}{|l|}{ Age, year } \\
\hline$<65$ & 1 & & & 1 & & \\
\hline $65-75$ & 0.749 & $(0.470-1.191)$ & 0.222 & 0.677 & $(0.399-1.151)$ & 0.15 \\
\hline $75-85$ & 1.447 & $(0.959-2.184)$ & 0.078 & 1.201 & $(0.725-1.992)$ & 0.477 \\
\hline$>85$ & 2.352 & $(1.640-3.373)$ & $<0.001$ & 1.7 & $(1.027-2.814)$ & $0.039 *$ \\
\hline \multicolumn{7}{|l|}{$\begin{array}{l}\text { Insurance } \\
\text { status }\end{array}$} \\
\hline $\begin{array}{l}\text { National health } \\
\text { insurance only }\end{array}$ & 1 & & & 1 & 1 & \\
\hline With Medicaid & 1.452 & $(1.131-1.864)$ & 0.003 & 0.988 & $(0.729-1.340)$ & 0.939 \\
\hline \multicolumn{7}{|l|}{$\begin{array}{l}\text { Living } \\
\text { conditions }\end{array}$} \\
\hline With family & 1 & & & 1 & 1 & \\
\hline Veterans home & 2.098 & $(1.003-4.108)$ & 0.046 & 1.707 & $(0.753-3.866)$ & 0.2 \\
\hline $\begin{array}{l}\text { Long-term care } \\
\text { facilities }\end{array}$ & 1.961 & $(1.162-3.308)$ & 0.012 & 1.88 & $(1.066-3.319)$ & 0.029 * \\
\hline Solitary living & 1.165 & $(0.709-1.915)$ & 0.546 & 1.544 & $(0.896-2.659)$ & 0.118 \\
\hline Others & 1.262 & $(0.518-3.077)$ & 0.608 & 1.533 & $(0.591-3.982)$ & 0.38 \\
\hline \multicolumn{7}{|l|}{ Smoker } \\
\hline $\begin{array}{l}\text { No } \\
\text { smoking/quit } \\
\text { smoking }\end{array}$ & 1 & & & 1 & & \\
\hline Current smoker & 0.602 & $(0.369-0.983)$ & 0.042 & 0.848 & $(0.497-1.447)$ & 0.545 \\
\hline \multicolumn{7}{|l|}{ TTAS } \\
\hline Non-urgent & 1 & & & 1 & & \\
\hline Urgent & 1.269 & $(0.931-1.731)$ & 0.132 & 1.162 & $(0.830-1.628)$ & 0.382 \\
\hline Emergent & 1.682 & $(1.236-2.290)$ & 0.001 & 1.413 & (1.005-1.985) & 0.046 \\
\hline \multicolumn{7}{|l|}{ Glasgow Coma } \\
\hline \multicolumn{7}{|l|}{ Scale } \\
\hline $13-15$ & 1 & & & 1 & & \\
\hline $5-12$ & 1.185 & $(0.906-1.550)$ & 0.215 & 0.816 & $(0.590-1.128)$ & 0.218 \\
\hline $3-4$ & 2 & (1.371-2.917) & $<0.001$ & 1.434 & $(0.924-2.226)$ & 0.108 \\
\hline \multicolumn{7}{|c|}{ Charlson Comorbidity Index } \\
\hline$\leq 3$ & 1 & & & 1 & & \\
\hline$\overline{4}-6$ & 2.935 & $(1.663-5.180)$ & $<0.001$ & 1.53 & $(0.780-3.000)$ & 0.216 \\
\hline$\geq 7$ & 2.822 & $(1.600-4.976)$ & $<0.001$ & 1.44 & $(0.732-2.832)$ & 0.291 \\
\hline \multicolumn{7}{|c|}{ APACHE II score at admission } \\
\hline $0-14$ & 1 & & & 1 & & \\
\hline $15-24$ & 1.352 & $(0.974-1.876)$ & 0.072 & 1.042 & $(0.713-1.524)$ & 0.83 \\
\hline$>24$ & 1.848 & $(1.307-2.613)$ & 0.001 & 1.167 & $(0.758-1.798)$ & 0.483 \\
\hline \multicolumn{7}{|c|}{ palliative care consultation screening items } \\
\hline A5 & 3.033 & $(1.592-5.780)$ & 0.001 & 2.128 & $(1.039-4.358)$ & 0.039 * \\
\hline A6 & 1.833 & (1.381-2.435) & $<0.001$ & 0.955 & (0.659-1.383) & 0.807 \\
\hline A7 & 1.77 & (1.353-2.317) & $<0.001$ & 0.956 & (0.673-1.357) & 0.8 \\
\hline A8 & 3.102 & $(1.630-5.903)$ & 0.001 & 1.674 & $(0.839-3.342)$ & 0.144 \\
\hline B1 & 2.469 & $(1.923-3.171)$ & $<0.001$ & 1.725 & (1.193-2.496) & 0.004 * \\
\hline B3 & 1.778 & $(1.366-2.314)$ & $<0.001$ & 1.181 & $(0.844-1.652)$ & 0.331 \\
\hline B4 & 1.678 & $(1.236-2.278)$ & 0.001 & 1.127 & $(0.791-1.606)$ & 0.508 \\
\hline B6 & 1.928 & $(1.049-3.542)$ & 0.035 & 1.194 & $(0.615-2.317)$ & 0.601 \\
\hline B7 & 2.478 & $(1.926-3.187)$ & $<0.001$ & 1.279 & $(0.815-2.007)$ & 0.284 \\
\hline B8 & 2.56 & $(1.329-4.929)$ & 0.005 & 2.42 & $(1.187-4.935)$ & $0.015^{*}$ \\
\hline
\end{tabular}

TTAS = Taiwan Triage and Acuity Scale; APACHE = Acute Physiology and Chronic Health Evaluation; OR = odds ratio; 95\% CI = 95\% confidence interval; AOR $=$ adjusted odds ratio; ${ }^{*} p<0.05$ is considered statistical significance in regression model. 
Table 4. Comparison of hospital care in hospitalization between 282 early DNR patients with mortality and 198 late DNR patients with mortality.

\begin{tabular}{|c|c|c|c|}
\hline \multirow[t]{2}{*}{ Variable } & $\begin{array}{c}\text { Early DNR Patients with } \\
\text { Mortality }\end{array}$ & $\begin{array}{c}\text { Late DNR Patients with } \\
\text { Mortality }\end{array}$ & \multirow[t]{2}{*}{$p$} \\
\hline & $n=282(\%)$ & $n=198(\%)$ & \\
\hline \multicolumn{4}{|l|}{ Place of death } \\
\hline Intensive care unit & 109 (38.7) & $73(36.9)$ & \multirow{4}{*}{0.446} \\
\hline Wards & $108(38.3)$ & $89(44.9)$ & \\
\hline Hospice unit & $31(11.0)$ & $17(8.6)$ & \\
\hline $\begin{array}{l}\text { Critical against advice } \\
\text { discharge }\end{array}$ & $34(12.1)$ & $19(9.6)$ & \\
\hline \multicolumn{4}{|l|}{ End-of-life care } \\
\hline ET intubation * & $44(15.6)$ & $79(39.9)$ & $<0.001$ \\
\hline CPR & $12(4.3)$ & $16(8.1)$ & 0.078 \\
\hline Epinephrine * & $56(19.9)$ & $60(30.3)$ & 0.009 \\
\hline Cardioversion or defibrillation & $7(2.5)$ & $5(2.5)$ & 0.976 \\
\hline Vasopressors & $183(64.9)$ & $138(69.7)$ & 0.271 \\
\hline Cardiac pacemaker & $3(1.1)$ & $1(0.5)$ & 0.507 \\
\hline Ventilator support * & $47(16.7)$ & $75(37.9)$ & $<0.001$ \\
\hline ECMO or IABP & $1(0.4)$ & $4(2.0)$ & 0.077 \\
\hline Withdrawal of ET tube & $11(3.9)$ & $10(5.1)$ & 0.544 \\
\hline Narcotics use * & $144(51.1)$ & $124(62.6)$ & 0.012 \\
\hline
\end{tabular}

Results expressed as number (\%) for categorical variables; ET = endotracheal; $\mathrm{CPR}=$ cardiopulmonary resuscitation; ECMO = extracorporeal membrane oxygenation; IABP = intra-aortic balloon pump; ${ }^{*} p<0.05$ is considered statistically significant using chi-squared analysis or Fisher's exact test.

Table 5. Multiple logistic regression analyses of hospital care between early DNR and late DNR patients with mortality

\begin{tabular}{ccccccc}
\hline \multirow{2}{*}{ Variable } & \multicolumn{3}{c}{ Univariate Analysis } & \multicolumn{3}{c}{ Multiple Logistic Regression } \\
\cline { 2 - 7 } & OR & $\mathbf{9 5 \% ~ C I ~}$ & $p$ & AOR & $\mathbf{9 5 \% ~ C I ~}$ & $p$ \\
\hline ET intubation * & 0.278 & $(0.181-0.428)$ & $<0.001$ & 0.198 & $(0.061-0.643)$ & 0.007 \\
Epinephrine & 0.570 & $(0.374-0.868)$ & 0.009 & 0.639 & $(0.404-1.010)$ & 0.055 \\
Ventilator support & 0.328 & $(0.214-0.502)$ & $<0.001$ & 1.460 & $(0.449-4.752)$ & 0.529 \\
Narcotics use * & 0.623 & $(0.430-0.902)$ & 0.012 & 0.518 & $(0.347-0.772)$ & 0.001 \\
\hline
\end{tabular}

ET = endotracheal; OR = odds ratio; $95 \% \mathrm{CI}=95 \%$ confidence interval; $\mathrm{AOR}=$ adjusted odds ratio; ${ }^{*} p<0.05$ is considered statistical significance in regression model.

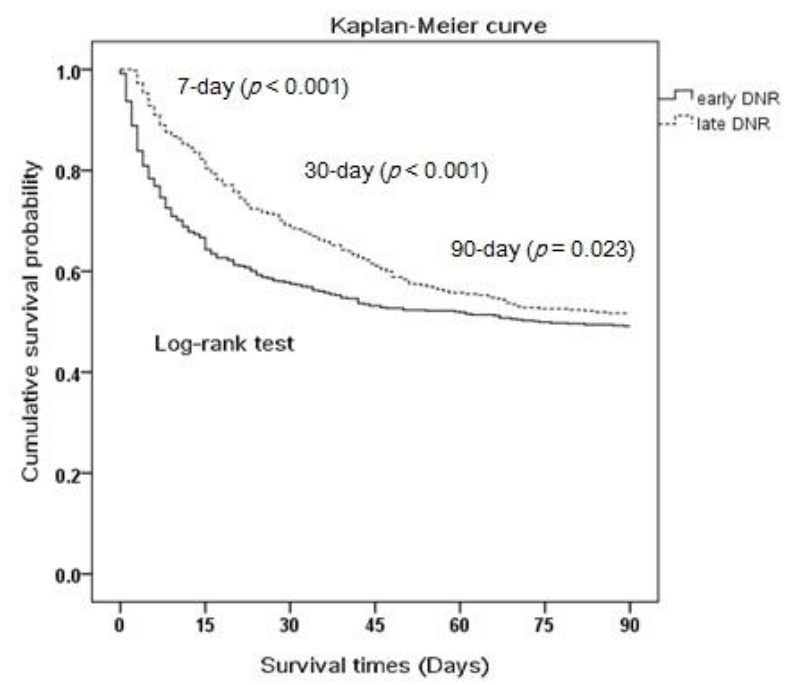

Figure 1. The cumulative survival curve of early DNR patients and late DNR patients. 


\section{Discussion}

The study found several differences in patient characteristics, hospital care, survival, and resource utilization between EDNR and LDNR patients.

\subsection{Characteristics}

Patient characteristics that predict EDNR were age $>85$ years, living in long-term care facilities, presence of advanced cardiovascular diseases (A5), "medical staff would not be surprised if the patient died within 12 months of this episode" (B1), and patients' family requesting PC (B8).

\subsection{Age}

Compatible with our finding that age $>85$ years was an independent risk factor for EDNR, other studies also found that older patients were more likely to have an EDNR order [11-13]. Age was a powerful predictor of an explicit DNR directive in all categories of patients older than 50 years of age [13]. Age $\geq 80$ years was an independent risk factor for DNR orders after controlling for comorbid conditions [14]. Other than being associated with more comorbidity, functional impairment, and higher mortality [14], older patients may have an opportunity to discuss with their physicians and families about advance directives and may be more likely to have accepted and expected their own mortality [15]. However, if decisions on EDNR are based purely on the patient's chronological age without factoring in survival, quality of life, or patients' wishes, it may be constituted as ageism. Our study confirmed that age is an important factor for EDNR in critically ill patients, but whether ageism, withholding treatment solely on the basis of age, plays a part in the decision-making process remains unclear.

\subsection{Living in Long-Term Care Facilities}

Our study found that patients living in long-term care facilities were more likely to have EDNR orders (AOR 1.880). Of the 74 patients from nursing homes in our study who signed a DNR order at the ED, 53 patients $(71.62 \%)$ had EDNR. Similarly, a Danish cohort of patients with community-acquired pneumonia (CAP) found patients with EDNR were older and more frequently nursing home residents $(41 \%$ vs. $6 \%, p<0.001)$. [16] Marrie et al., found that coming from a chronic care facility or a nursing home was a major demographic associated with DNR upon admission, and more than half (53.8\%) from institutions had a DNR order in place on admission [17]. This may reflect nursing home policies or a greater awareness among this group to have advanced directives. However, the prevalence of DNR directives among Taiwanese nursing home residents was lower than that in other countries [18]. The EDNR status associated with long-term care facilities may be due to physicians' awareness of the poor outcomes of resuscitation for nursing home patients and lower odds of achieving return of spontaneous circulation (ROSC) [19] and more likely to approach family and surrogates early with DNR discussion.

\subsection{Advanced Cardiovascular Disease}

Our study found that presence of advanced cardiovascular diseases (chronic heart failure (CHF, New York Heart Association III or IV), chest pain, or dyspnea while performing minimal exercise or on minimal exertion, or devastating inoperable peripheral vascular diseases) were a strong predictor of EDNR (AOR 2.128). EOL discussion in patients with heart failure (HF) is of particular importance because patients often experience repeated hospitalizations and a progressive decline in quality of life as they approach death [20]. However, the waxing and waning pattern typical in HF makes it difficult to accurately prognosticate expected survival, rendering it difficult for physicians to approach patients and surrogates with DNR discussions. Moreover, patients with HF were found to have frequent changes in code status, underscoring the importance of periodically reviewing resuscitation preferences as advocated by the American Heart Association [21]. A study found that three-quarters of community patients with HF elect DNR before death; 
however, changes in resuscitation preference are often made in the hospital in the final days to weeks of life [22]. This discordance with our finding that patients with HF are at higher risk for EDNR may be because our study included patients who were older (mean $80.8 \pm 14.2$ years) and had more advanced disease (CCI $\geq 747.8 \%)$. This may explain the early DNR order in CHF patients with advanced age that tend to underestimate their life expectancy [23].

\subsection{Medical Staff Would Not Be Surprised If the Patient Died within 12 Months}

The decision to forgo resuscitative measures should reflect patient values and preferences. However, physicians' judgments on patient condition and survival may have a direct impact on patients' preference for DNR decisions. Many patients and surrogates require a discussion on prognosis with their physicians prior to making a DNR decision [24]. Our study found that the factor "medical staff would not be surprised if the patient died within 12 months of this episode" was a risk factor for EDNR. In line with our study results, a multicenter study found that the one of the strongest predictors of DNR directives were physician prediction of low probability of survival. It is not only physician predictions of high likelihood of death that were associated with DNR order but also moderate likelihood of death [12]. The question "should physician's judgments on patient survival influence DNR decision?", is an ethical dilemma.

\subsection{Patients' Family Requesting Palliative Care}

Our study found that "patients' family requesting palliative care" is a predictor of EDNR. Inability to participate in decision-making was a strong predictor of a DNR directive during the first $24 \mathrm{~h}$ of ICU admission [13]. Patients who were unable to participate in decision-making were significantly more likely to have a DNR directive than a resuscitate directive [13]. A Taiwanese study revealed that the prevalence of DNR directives among Taiwanese nursing home residents was lower than in other countries, with $91 \%$ of the directives being put in place by family surrogates [18]. Other studies have shown that as many as $40 \%$ of hospitalized adults are unable to make their own medical decisions [25], with DNR decisions being made by family one-third of the time [26]. This is consistent with our finding that $59.4 \%$ of patients with DNR and $68.5 \%$ with EDNR were categorized as requiring assistance in terms of medical decisions, who were unable to participate in DNR decision making.

\subsection{Hospital Care}

Our study found that EDNR is associated with decreased ET intubation, epinephrine injection, ventilator support, and narcotic use, but no difference in CPR, cardioversion, vasopressor use, cardiac pacemaker insertion, ECMO, intraaortic balloon pumping (IABP), or withdrawal of ET tube was found compared to that in LDNR. This is similar to a sepsis study where the DNR group did not receive less ancillary care of the central line, vasopressors, blood transfusion, emergent hemodialysis, or surgery [11]. Our findings are also comparable with a study where chronic obstruction pulmonary disease (COPD)decedents with EDNR were less likely to undergo invasive mechanical ventilator support during their terminal hospitalization [27]. In theory, the DNR order itself should not directly impact care until the moment of cardiac arrest. However, one study found that EDNR directly influenced both resuscitative and ancillary care, with fewer invasive interventions being performed in the last week of life, including dialysis, mechanical ventilation, feeding tubes, and CPR, compared to those with LDNR and no DNR [6]. Another study on out-of-hospital cardiac arrest (OHCA) patients found that EDNR is associated with a significant decrease in potentially critical therapeutic options, including cardiac catheterization, bypass surgery, and blood transfusion after resuscitation, and is associated with less aggressive hospital care, fewer potentially beneficial procedures, and worse survival [3]. The impact of EDNR on both resuscitative measures and ancillary care may be that patients with DNR, are also less likely to receive nonbeneficial aggressive care at the end of life [28] and are more 
likely to receive care consistent with their preferences [29]. This wide variability in practice patterns between hospitals and physicians suggests a lack of standardized approach to the EDNR order and subsequent resuscitative measures and ancillary care. This further emphasizes the importance of communication between physicians and patients to align care with treatment goals. Physicians should be careful not to interpret DNR, which is "do not perform CPR in the event of cardiac arrest" as "do not actively treat this patient."

In contrast to a study in which nurses were more comfortable giving opioids for pain management at the EOL [6], our study found that EDNR is associated with decreased narcotic use. We hypothesize that the shorter duration from DNR placement to death and shorter hospital LOS associated with EDNR allowed less time for physicians to address the family members on patients' comfort during the care. This certainly leaves room for improvement in patient comfort during hospital care, especially in patients with an EDNR order.

\subsection{Survival}

Patients with EDNR had lower 7-, 30-, and 90-day survival; our finding is compatible with another study where EDNR was found to be an independent predictor for 28-day mortality [7]. In a Danish cohort of patients with community acquired pneumonia (CAP), EDNR was associated with higher mortality after adjustment for clinical risk factors [16]. Among intracerebral hemorrhage $(\mathrm{ICH})$ patients, EDNR is an independent predictor of poor outcome [30,31]; 2.6 times more likely to die than those without DNR order [30]. OHCA patients with EDNR usually die in the hospital without discharge to home within one day of admission [3]. Moreover, EDNR order is often a proxy of the patient's underlying disease, prehospital frailty, and burden of comorbidities [4] that is not captured by the established risk factors for mortality. Hence, EDNR may function as a composite of prognostic variables, resulting in a strong prediction of short-term mortality risk [8]. However, other studies have argued otherwise. In one study, patients with LDNR (written on day 6 or later) were twice as likely to die in the hospital than patients with EDNR. [32] Marrie et al., hypothesized that EDNR reflects comorbidities and the general health status of a patient, while LDNR represents a lack of response to treatment and comorbidity [17]. The LDNR discussion that occurred later may be because patients are not responding to treatment and at imminent risk of death. A study on sepsis, in fact, found better outcomes in the EDNR group than that in the LDNR group [11]. It remains unclear if the EDNR in our study directly reflects general health status or LDNR directly reflects a lack of response to treatment. The nature and breadth of the discussion leading to EDNR, LDNR, and subsequent withdrawal of care are beyond the scope of the study, leaving room for further research.

\subsection{Resource Utilization}

Patients with EDNR had decreased hospital length of stay (LOS) (17.8 \pm 18.4 days vs. $30.3 \pm 31.7$ days) and decreased total medical expenditure $(246,684 \pm 266,447$ NTD vs. $468,532 \pm 476,382$ ) compared to LDNR patients, which is compatible with other studies. One study on COPD patients found that the average total medical cost during the last hospitalization was nearly twofold greater for LDNR than for EDNR decedents [27]. We further stratified patients into mortality and survival groups. Among patients with mortality, the hospital LOS in EDNR patients was shorter than LDNR. (11.7 \pm 16.4 days vs. $25.2 \pm 24.5$ days, $p<0.001)$. The lower probability of survival in EDNR compared to LDNR (Figure 1) may explain the shorter hospital LOS. Surprisingly however, among patients who survived, EDNR had a shorter hospital LOS (faster recovery) than LDNR $(22.9 \pm 18.5$ vs. $3.4 \pm 36, p<0.001)$. The finding agrees with Marrie et al.'s hypothesis that LDNR may be a result of poor response to treatment and comorbidity [17] hence patients with LDNR who survived may have a prolonged hospital course.

\section{Limitations}

Our study has several limitations. First, as a retrospective study, it is liable to underreport due to missing or incomplete medical records. Second, although the inclusion criteria 
were strictly followed, there still may exist confounding discrepancies between the criteria and clinical conditions of patients recruited. Third, although the study determined the differences in hospital care and outcome between EDNR and LDNR, it did not stratify patients into subgroups based on diagnoses such as ICH, OHCA, CAP, etc. Fourth, the study determined the patient characteristics associated with EDNR, but the rationale for selecting EDNR and LDNR remains unclear in these patients. Fifth, the study did not assess psychosocial aspects such as patient and surrogate viewpoints, their satisfaction or dissatisfaction, and patients' quality of death associated with EDNR.

\section{Conclusions}

Physicians should understand the potential impact on hospital care and survival associated with EDNR to tailor care with treatment goals. Patients who have not had this discussion should be made aware that EDNR is associated with decreased ET intubation, reduced epinephrine injection, ventilator support, and narcotic use during hospital care, decreased length of hospital stay, hospital expenditure, and decreased survival.

While EDNR orders may be appropriate for guiding subsequent treatment, EDNR may not be entirely appropriate in certain groups of patients in whom long-term prognosis is difficult to ascertain and $24 \mathrm{~h}$ may be premature to make this decision.

Author Contributions: J.C.-Y.C. interpretation of data, drafted the article, revise it critically for important intellectual content; C.Y.: concept and design of the study, acquisition of data; L.-L.L.: concept and design of the study, acuqisiton of data; Y.-J.C.: concept and design of the study, analysis and interpretation of data; H.-H.H.: concept and design of the study, analysis and interpretation of data; J.-S.F.: concept and design of the study, interpretation of data; T.-F.H.: concept and design of the work, interpretation of data; D.H.-T.Y.: concept and design of the work, interpretation of data, revise it, critically for important intellectual content, approved the published version. All authors have read and agreed to the published version of the manuscript.

Funding: This study was supported partly by research grants MOST107-2314-B-075-053 and MOST 108-2314-B-075-034 (D.H.-T.Y.) from the Ministry of Science and Technology, Taiwan, and 107VACS002, V108C-123, and V109C-046 (D.H.-T.Y.) from Taipei Veterans General Hospital, Taiwan.

Institutional Review Board Statement: The study was conducted according to the guidelines of the Declaration of Helsinki, and approved by the Institutional Review Board of Taipei Veterans General Hospital, IRB No: 2020-11-010BC.

Informed Consent Statement: The study was approved by the Institutional Review Board of Taipei Veterans General Hospital, which waived the need for patient consent.

Data Availability Statement: All data submitted comply with Institutional or Ethical Review Board requirements and applicable government regulations. For further information, please contact David Hung-Tsang Yen (hjyen@vghtpe.gov.tw).

Conflicts of Interest: The authors declare that there is no conflict of interest. 
Appendix A

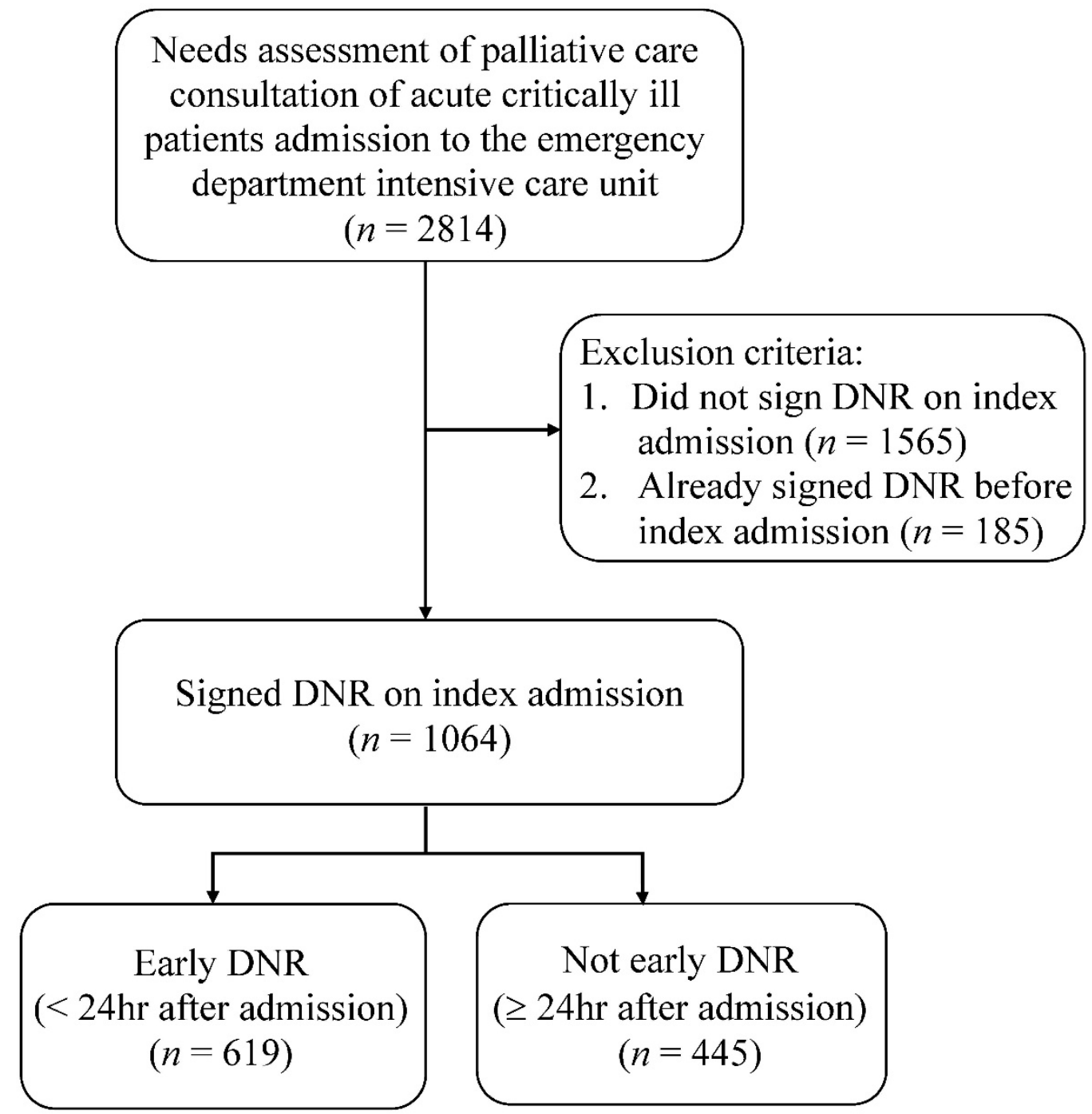

Figure A1. Flow shart on patient selection.

\section{References}

1. Rabkin, M.T.; Gillerman, G.; Rice, N.R. Orders not to resuscitate. N. Engl. J. Med. 1976, 295, 364-366. [CrossRef] [PubMed]

2. Tomlinson, T.; Brody, H. Ethics and communication in do-not-resuscitate orders. N. Engl. J. Med. 1988, 318, 43-46. [CrossRef] [PubMed]

3. Richardson, D.K.; Zive, D.; Daya, M.; Newgard, C.D. The impact of early do not resuscitate (DNR) orders on patient care and outcomes following resuscitation from out of hospital cardiac arrest. Resuscitation 2013, 84, 483-487. [CrossRef] [PubMed]

4. Zingmond, D.S.; Wenger, N.S. Regional and institutional variation in the initiation of early do-not-resuscitate orders. Arch. Intern. Med. 2005, 165, 1705-1712. [CrossRef] [PubMed]

5. Auerbach, A.D.; Katz, R.; Pantilat, S.Z.; Bernacki, R.; Schnipper, J.; Kaboli, P.; Wetterneck, T.; Gonzales, D.; Arora, V.; Zhang, J.; et al. Factors associated with discussion of care plans and code status at the time of hospital admission: Results from the multicenter hospitalist study. J. Hosp. Med. 2008, 3, 437-445. [CrossRef] [PubMed]

6. $\quad$ Ouyang, D.J.; Lief, L.; Russell, D.; Xu, J.; Berlin, D.A.; Gentzler, E.; Su, A.; Cooper, Z.R.; Senglaub, S.S.; Maciejewski, P.K.; et al. Timing is everything: Early do-not-resuscitate orders in the intensive care unit and patient outcomes. PLoS ONE 2020, 15, e0227971. [CrossRef]

7. Fuchs, L.; Anstey, M.; Feng, M.; Toledano, R.; Kogan, S.; Howell, M.D.; Clardy, P.; Celi, L.; Talmor, D.; Novack, V. Quantifying the Mortality Impact of Do-Not-Resuscitate Orders in the ICU. Crit. Care Med. 2017, 45, 1019-1027. [CrossRef]

8. Baldwin, M.R.; Narain, W.R.; Wunsch, H.; Schluger, N.W.; Cooke, J.T.; Maurer, M.S.; Rowe, J.W.; Ledere, D.J.; Bach, P.B. A prognostic model for 6-month mortality in elderly survivors of critical illness. Chest 2013, 143, 910-919. [CrossRef]

9. $\quad$ Fu, K.H.; Chen, Y.R.; Fan, J.S.; Chen, Y.C.; Huang, H.H.; How, C.K.; Yen, D.H.-T.; Chen, S.-A.; Huang, M.-S. Emergency department critical care unit for critically ill cardiovascular patients: An observation study. J. Chin. Med. Assoc. 2017, 80, 233-244. [CrossRef] 
10. Yang, C.; Yang, T.T.; Tsou, Y.J.; Lin, M.H.; Fan, J.S.; Huang, H.H.; Tsai, M.C.; Yen, D.H. Initiating palliative care consultation for acute critically ill patients in the emergency department intensive care unit. J. Chin. Med. Assoc. 2020, 83, 500-506. [CrossRef]

11. Chang, Y.C.; Fang, Y.T.; Chen, H.C.; Lin, C.Y.; Chang, Y.P.; Chen, Y.M.; Huang, C.H.; Huang, K.T.; Chang, H.C.; Su, M.C.; et al. Effect of do-not-resuscitate orders on patients with sepsis in the medical intensive care unit: A retrospective, observational and propensity score-matched study in a tertiary referral hospital in Taiwan. BMJ Open 2019, 9, e029041. [CrossRef] [PubMed]

12. Sinuff, T.; Cook, D.J.; Rocker, G.M.; Griffith, L.E.; Walter, S.D.; Fisher, M.M.; Dodek, P.M.; Sjokvist, P.; McDonald, E.; Marshall, J.C.; et al. Level of Care Study Investigators \& the Canadian Critical Care Trials Group. DNR directives are established early in mechanically ventilated intensive care unit patients. Can. J. Anaesth. 2004, 51, 1034-1041. [PubMed]

13. Cook, D.J.; Guyatt, G.; Rocker, G.; Sjokvist, P.; Weaver, B.; Dodek, P.; Marshall, J.; Leasa, D.; Levy, M.; Varon, J.; et al. Cardiopulmonary resuscitation directives on admission to intensive care unit: An international observational study. Lancet 2001, 358, 1941-1945. [CrossRef]

14. Al-Dorzi, H.M.; Tamim, H.M.; Mundekkadan, S.; Sohail, M.R.; Arabi, Y.M. Characteristics, management and outcomes of critically ill patients who are 80 years and older: A retrospective comparative cohort study. BMC Anesthesiol. 2014, 14, 126. [CrossRef] [PubMed]

15. Sharp, T.; Moran, E.; Kuhn, I.; Barclay, S. Do the elderly have a voice? Advance care planning discussions with frail and older individuals: A systematic literature review and narrative synthesis. Br. J. Gen. Pract. 2013, 63, e657-e668. [CrossRef] [PubMed]

16. Egelund, G.B.; Jensen, A.V.; Petersen, P.T.; Andersen, S.B.; Lindhardt, B.Ø.; Rohde, G.; Ravn, P.; von Plessen, C. Do-not-resuscitate orders in patients with community-acquired pneumonia: A retrospective study. BMC Pulm. Med. 2020, 20, 201. [CrossRef]

17. Marrie, T.J.; Fine, M.J.; Kapoor, W.N.; Coley, C.M.; Singer, D.E.; Obrosky, D.S. Community-acquired pneumonia and do not resuscitate orders. J. Am. Geriatr. Soc. 2002, 50, 290-299. [CrossRef]

18. Lo, Y.T.; Wang, J.J.; Liu, L.F.; Wang, C.N. Prevalence and related factors of do-not-resuscitate directives among nursing home residents in Taiwan. J. Am. Med. Dir. Assoc. 2010, 11, 436-442. [CrossRef]

19. Abbo, E.D.; Yuen, T.C.; Buhrmester, L.; Geocadin, R.; Volandes, A.E.; Siddique, J.; Edelson, D.P. Cardiopulmonary resuscitation outcomes in hospitalized community-dwelling individuals and nursing home residents based on activities of daily living. J. Am. Geriatr. Soc. 2013, 61, 34-39. [CrossRef]

20. Dunlay, S.M.; Redfield, M.M.; Weston, S.A.; Therneau, T.M.; Hall Long, K.; Shah, N.D.; Roger, V.L. Hospitalizations after heart failure diagnosis a community perspective. J. Am. Coll. Cardiol. 2009, 54, 1695-1702. [CrossRef]

21. Allen, L.A.; Stevenson, L.W.; Grady, K.L.; Goldstein, N.E.; Matlock, D.D.; Arnold, R.M.; Cook, N.R.; Felker, G.M.; Francis, G.S.; Hauptman, P.J.; et al. American Heart Association; Council on Quality of Care and Outcomes Research; Council on Cardiovascular Nursing; Council on Clinical Cardiology; Council on Cardiovascular Radiology and Intervention; Council on Cardiovascular Surgery and Anesthesia. Decision making in advanced heart failure: A scientific statement from the American Heart Association. Circulation 2012, 125, 1928-1952. [PubMed]

22. Dunlay, S.M.; Swetz, K.M.; Redfield, M.M.; Mueller, P.S.; Roger, V.L. Resuscitation preferences in community patients with heart failure. Circ. Cardiovasc. Qual. Outcomes 2014, 7, 353-359. [CrossRef] [PubMed]

23. Allen, L.A.; Yager, J.E.; Funk, M.J.; Levy, W.C.; Tulsky, J.A.; Bowers, M.T.; Dodson, G.C.; O'Connor, C.M.; Felker, G.M. Discordance between patient-predicted and model-predicted life expectancy among ambulatory patients with heart failure. JAMA 2008, 299, 2533-2542. [CrossRef] [PubMed]

24. Agård, A.; Hermerén, G.; Herlitz, J. Should cardiopulmonary resuscitation be performed on patients with heart failure? The role of the patient in the decision-making process. J. Intern. Med. 2000, 248, 279-286. [CrossRef]

25. Raymont, V.; Bingley, W.; Buchanan, A.; David, A.S.; Hayward, P.; Wessely, S.; Hotopf, M. Prevalence of mental incapacity in medical inpatients and associated risk factors: Cross-sectional study. Lancet 2004, 364, 1421-1427. [CrossRef]

26. Levin, T.T.; Li, Y.; Weiner, J.S.; Lewis, F.; Bartell, A.; Piercy, J.; Kissane, D.W. How do-not-resuscitate orders are utilized in cancer patients:Timing relative to death and communication-training implications. Palliat. Support Care 2008, 6, 341-348. [CrossRef]

27. Fu, P.K.; Yang, M.C.; Wang, C.Y.; Lin, S.P.; Kuo, C.T.; Hsu, C.Y.; Tung, Y.C. Early Do-Not-Resuscitate Directives Decrease Invasive Procedures and Health Care Expenses during the Final Hospitalization of Life of COPD Patients. J. Pain Symptom Manag. 2019, 58, 968-976. [CrossRef]

28. Loggers, E.T.; Maciejewski, P.K.; Jimenez, R.; Nilsson, M.; Paulk, E.; Stieglitz, H.; Prigerson, H.G. Predictors of intensive end-of-life and hospice care in Latino and white advanced cancer patients. J. Palliat. Med. 2013, 16, 1249-1254. [CrossRef]

29. Detering, K.M.; Hancock, A.D.; Reade, M.C.; Silvester, W. The impact of advance care planning on end of lifecare in elderly patients: Randomised controlled trial. BMJ 2010, 340, c1345. [CrossRef]

30. Claude Hemphill, J., III; Newman, J.; Zhao, S.; Johnston, S.C. Hospital usage of early do-not-resuscitate orders and outcome after intracerebral hemorrhage. Stroke 2004, 35, 1130-1134. [CrossRef]

31. Becker, K.J.; Baxter, A.B.; Cohen, W.A.; Bybee, H.M.; Tirschwell, D.L.; Newell, D.W.; Winn, H.R.; Longstreth, W.T., Jr. Withdrawal of support in intracerebral hemorrhage may lead to selffulfilling prophecies. Neurology 2001, 56, 766-772. [CrossRef] [PubMed]

32. Torke, A.M.; Sachs, G.A.; Helft, P.R.; Petronio, S.; Purnell, C.; Hui, S.; Callahan, C.M. Timing of do-not-resuscitate orders for hospitalized older adults who require a surrogate decision-maker. J. Am. Geriatr. Soc. 2011, 59, 1326-1331. [CrossRef] [PubMed] 